\title{
GRAIN SIZE-RELATED CHARACTERIZATION OF VARIOUS NON-HAZARDOUS MUNICIPAL AND COMMERCIAL WASTE FOR SOLID RECOVERED FUEL (SRF) PRODUCTION
}

\author{
Alexander Curtis *, Josef Adam, Roland Pomberger and Renato Sarc
}

Montanuniversitat Leoben Department fur Umwelt- und Energieverfahrentechnik Ringgold standard institution - Chair of Waste Processing Technology and Waste Management Franz-Josef-Strasse 18, Leoben 8700 Austria

Article Info:

Received:

21 June 2019

Revised:

18 July 2019

Accepted:

24 July 2019

Available online:

26 September 2019

Keywords:

Solid Recovered Fuel

Grain size-related characterization

Screening

Commercial waste

Municipal waste

\begin{abstract}
This article deals with studies on the grain size-related characterization of various types of waste for the production of Solid Recovered Fuel (SRF) for the cement industry. By implementing a suitable combination of the mechanical processes and adjusting the proportions of the waste types used, different properties of SRF in certain parameters can be set. In addition to the process technology, the treated solid waste types themselves have the greatest impact on the final quality of SRF. Here, the practical investigation for the characterization of various grain size classes generated of different solid waste types (packaging waste and commercial waste) used for the production of SRF is described. These investigations have been divided into a series of tests (12) with an industrial waste screen and in further tests with a laboratory screen and chemical analyses of all of the produced grain size classes. The mass distribution of the investigated grain size classes for each type of waste show significant differences. As assumed, the parameters calorific value and dry mass content of all types of waste increase with growing grain size. For most heavy metals and chlorine, no clear trend can be shown. For example, nickel accumulates in the commercial waste types in the grain size class $0-20 \mathrm{~mm}$, in the packaging waste in class $>65 \mathrm{~mm}$. The data on waste input material and generation of proper input waste mix is required for production of quality assured and homogeneous SRF for energy recovery in cement industry.
\end{abstract}

\section{INTRODUCTION}

The introductory chapter describes in more detail the quality criteria for waste for the production of substitute fuels for use in the cement industry in Austria.

The cement production process is quite energy-intensive with 3,839 GJ per tonne of clinker (Mauschitz, 2018), which is why the search for alternatives for the standard fossil fuels such as coal has been going on for quite some time now. The thermal substitution rate, that is to say the share of energy from solid recovered fuels (SRF) that are burned instead of primary standard fuels (e.g. coal) in relation to the demand for energy in a cement production facility, was at $80.6 \%$ (Mauschitz, 2018) in the year 2017. In order to attain this high substitution rate, the input of energy in the cement production process must occur in several stages (primary firing, calciner firing, rotary kiln inlet) with various substitute fuels (Sarc et al., 2015). The SRF being used at the input positions must be adjusted with regard to its chemical (heavy metals, chlorine) and physical parame- ters (calorific value, grain size distribution).

On the one hand, the SRF used must meet the facility's own quality criteria as well as the criteria for the heavy metals ( $\mathrm{Sb}, \mathrm{As}, \mathrm{Pb}, \mathrm{Cd}, \mathrm{Cr}, \mathrm{Co}, \mathrm{Ni}$, and $\mathrm{Hg}$ ) for the threshold values as per the Austrian Incineration Ordinance (AVV) (Bundeskanzleramt, 2010). The facility's own quality requirements for SRF are to ensure that even with a high degree of substitution both process stability and product quality are to be guaranteed. The demands on the SRF for use in the primary firing are particularly high. The input of SRF into the rotary kiln via the primary firing, is carried out pneumatically via a channel on the burner gun and this must incinerate completely within a quite brief retention time, during the trajectory. With an optimal burn-out, only incombustible fuel components (i.e. ashes) get into the clinker and are then utilized materially (from a technical point of view). Any changes in the fuel properties have an impact on the conveying characteristics, the dosing, the burn-out behaviour, the flame form, the flame temperature, the clinker quality, etc., and are thus able to be determined by means of si- 
mulations and practical tests and to be carefully coordinated with the operator of the cement facility. The demands on a calciner fuel are not as high, however, this SRF also has to fulfil many criteria (e.g. calorific value, chlorine content). For the production of SRF for the cement industry, the most various combustible materials are put to use. A large part of these are commercial waste of the most various pre-treatment intensity or residual fractions from sorting packaging waste. Further fundamental and subject-specific statements on the topic of the production of SRF for energy-oriented exhaustion in the cement industry as well as on the topic of quality assurance and the normal market qualities have been described and discussed by Lorber et al. (2012), Sarc et al. (2013), Sarc et al. (2014) and Aldrian et al. (2016). The aim of the present work was to determine the combustion properties as well as the concentration of heavy metals in different grain size classes in comparison to the legal limits for waste types suitable for SRF production.

\section{MATERIALS AND METHODS}

The extensive tests with an industrial screen were conducted between March and May 2018 on the premises of a waste treatment plant in Austria. The subsequent screening trials and chemical analyses of each of the individual screen fractions were conducted during the same time period in the laboratory of the Chair of Waste Processing Technology and Waste Management of the Montanuniversitaet Leoben.

\subsection{Test Material}

Four input materials important for SRF production were tested, whereby one of these was from packaging waste (PW): F1 (PW) and the other three materials were from mixed commercial waste (MCW): F2 (MCW 1), F3 (MCW 2), F4 (MCW 3) (note: F = fraction).

Quality assured, high-calorific and medium-calorific SRF ready for incineration for the use in the cement facilities are able to be produced from these input materials by means of suitable mechanical treatment steps.

\subsubsection{F1 (Packaging Waste PW)}

The fraction $\mathrm{F} 1$ is the sorting residue from the processing of plastic packaging waste. Due to the standardized collection and processing (defined requirements such as quotas) the material is rather homogeneous. The test material comes from several sorting facilities in Austria and neighbouring countries. Large plastic films, hollow items, metals and in part the fine contents (approx. $40 \mathrm{~mm}$ ) are separated from the entire mixed packaging waste in the sorting process. The remaining sorting residue consists of smaller, partly more highly soiled sheets of plastic, paper, cardboard, small hollow plastic items which, due to the high plastic content, exhibits a high calorific value $(>20$ MJ/kgOS).Performed Tests: T1, T2, T3.

\subsubsection{F2 (Mixed Commercial Waste 1)}

The fraction F2 consists of mixed commercial waste, household trash and bulky materials and comes from Austria. The material was subject to ground sorting, whereby approx. $10-15 \%$ recyclable material (wood, metals, rigid plastics (buckets used in the construction industry, etc.), plastic films and impurities (inert)) were separated and came from commercial enterprises in Graz and its surroundings. It contained high amounts of plastic films and fine contents. The material was quite inhomogeneous, which is something that was reflected in the results of the tests. Performed Tests: T5, T7, T8, T13.

\subsubsection{F3 (Mixed Commercial Waste 2)}

The fraction F3 consists of mixed processed commercial waste (Mixed Commercial Waste) and came from various processing facilities in neighbouring country 1 . Most of the recyclable materials and impurities were already separated in the processing facilities. Performed Tests: T4, T6, T9.

\subsubsection{F4 (Mixed Commercial Waste 3)}

The fraction F4 consists of mixed commercial waste (Mixed Commercial Waste) and came from various processing facilities in neighbouring country 2 . Most of the recyclable materials and impurities were already separated in the processing facilities. Performed Tests: T12, T14.

The individual tests conducted and the abbreviations used

Three to five screening trials each were conducted with each of the four input materials (F1 to F4, with two tonnes of test material for each test) with an industrial waste screen (IFE circular vibratory screen) with a screen deck with 65 $\mathrm{mm}$ screen cut and a screen deck with $10 \mathrm{~mm}$ mesh size. As has already been mentioned, additional screen categories were produced in the laboratory.

Each individual test was abbreviated with the letter $\mathrm{T}$ and in addition to that with a serial number (in chronological order) e.g.T12 (test number). A 2 tonne sample of the various types of waste (i.e. F1, F2, F3, and F4) was examined for each test. Since several individual tests were conducted for each type of waste, the name of the respective test materials is comprised of the name of the type of waste and the test number, e.g. F4 T12.

\section{Examples (compare Figure 2):}

F4 T12 is thus the test material of the total of the twelfth test and the first 2 tonne sample of the type of waste F4.

F4 T14 is thus the test material of the total of the fourteenth test and the second 2 tonne sample of the type of waste F4.

\subsection{Methods}

The following chapters describe the trial scheme, the test materials and the procedure for the implementation of the examinations on site and in the laboratory.

\subsubsection{Test scheme}

To obtain a better overview the following Figure 1 illustrates the process of the entire tests conducted.

\subsubsection{Test Material}

Initially sample material was collected from each type of waste (F1, F2, F3, F4) observed and placed in interme- 


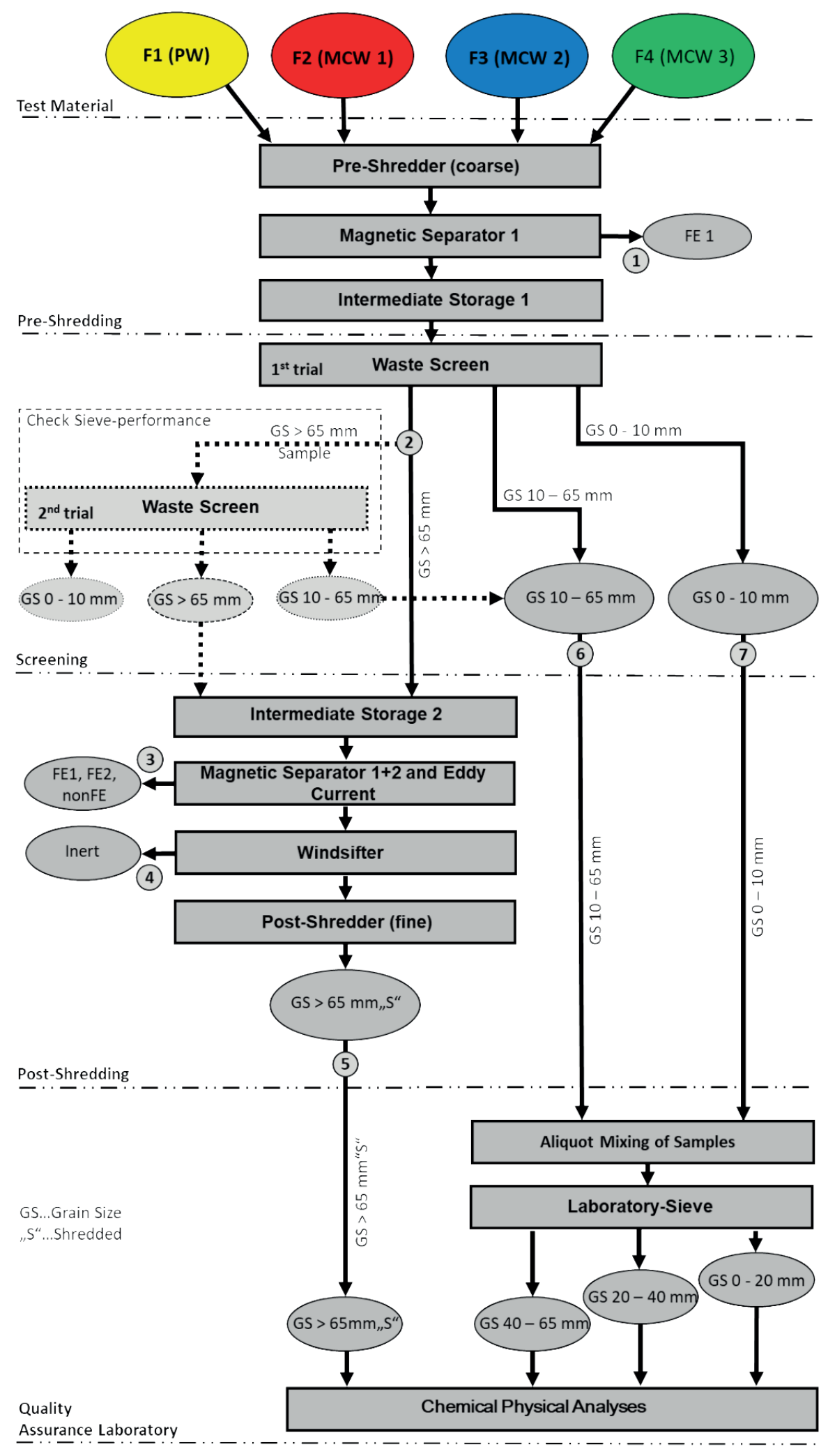

FIGURE 1: Trial scheme with locations of samples taken.

diate storage. Approx. two tonnes of test material was made available for each of the 12 observed tests.

\subsubsection{Pre-Shredding}

The previously described test materials were stored separately and pre-shredded coarsely using a pre-shredder (grain size (GS) $350 \mathrm{~mm}$ ), at the same time iron being separated using the magnetic separator $1 \mathrm{FE} 1$ (iron) and samples were taken at sampling location 1 . The pre-shredded test material was weighed and placed in intermediate 
storage 1.

The pre-shredder was a low speed device manufactured by the Lindner Recyclingtech Company.

Name: Meteor 2500

Screening basket: screening brace with $110 \mathrm{~mm}$ gap

Revolutions per minute: $50 \mathrm{rpm}$

Blade: Trapezoid blades in good condition

\subsubsection{Screening}

The test materials coarsely pre-shredded were taken from the intermediate storage bunker 1 and, using a wheel loader and with manual support (dosage) were transported on a conveyor belt to the waste screen. A mechanical dosage device, which guarantees even a dosage of the test materials used, will not be available on the market anytime in the near future (Feil et al., 2018). The quality of the manual dosage is not optimal, it is however, for lack of alternatives, the only possibility to place the material onto the circular vibratory screen fairly evenly. A direct interconnection of the pre-shredders with the circular vibratory screen was not possible for technical reasons. The possibility of using one of the additional shredders as a dosage device was discussed, however this idea was dismissed since the already pre-shredded material would have had to undergo an additional shredding step.

\section{Waste screen used}

The waste screen from the IFE Aufbereitungstechnik $\mathrm{GmbH}$ Company used is a double deck circular vibratory screen machine with waste screens (eight individual screen segments arranged in four stages) on the upper deck and the resonance system VARIOMAT with polymer screening mats on the lower deck.

Data and Name of the waste screen:

Name/Type: Waste Screen SMV 1200x4000 F-UW24

Unbalance shaft drive: $\mathrm{P}=18.5 \mathrm{~kW} ; \mathrm{n}=740 \mathrm{rpm}$

Frequency: $f=9-14 \mathrm{~Hz}$

Total weight: $\mathrm{mges}=6,300 \mathrm{~kg}$

Vibrating mass: $\mathrm{mvib}=4,170 \mathrm{~kg}$

The width of the screening holes was $83 \mathrm{~mm}$. Tilting the waste screen segments caused smaller effective screening holes (projected surface) which in this case corresponds to a $65 \mathrm{~mm}$ screen cut. Tests with the grain size GS $10-65 \mathrm{~mm}$ using these waste screening segments revealed that $95 \%$ of the particles were smaller than $65 \mathrm{~mm}$. Thus, in the remaining part of the article the screen cut of $65 \mathrm{~mm}$ will be specified for these screening stages. The laboratory screening machine is specified with the actual screening hole diameter (20 $\mathrm{mm}$ and $40 \mathrm{~mm}$ ).

The upper deck of the waste screen is equipped with eight screening segments and the total surface was $5 \mathrm{~m}^{2}$. Six of the screening segments with a $65 \mathrm{~mm}$ screen cut had a screening surface area of $3.75 \mathrm{~m}^{2}$, and two screening segments with $45 \mathrm{~mm}$ wide screening holes situated on the screening inlet, had a surface of $1.25 \mathrm{~m}^{2}$.

On the lower deck there were polymer screening mats with squared screening holes of $10 \mathrm{~mm}$ built in (Resonance system VARIOMAT) (IFE Aufbereitungstechnik $\mathrm{GmbH}$, 2019). The grain size GS $0-10 \mathrm{~mm}$ separated with the lo- wer deck was caught by means of 600 Liter plastic boxes, taken into consideration in the weight assessment, mixed aliquot with the grain size GS $10-65 \mathrm{~mm}$ in the laboratory to create the grain size GS $0-65 \mathrm{~mm}$ for further lab screening.

\section{Tests}

The test duration was approx. 1 hour for the each of the two tonnes test materials, which corresponds to a screening throughput of $0.4 \mathrm{t} /\left(\mathrm{m}^{2 *} \mathrm{~h}\right)$. The throughput of the screening for these materials is approx. $0.8 \mathrm{t} /\left(\mathrm{m}^{2 *} \mathrm{~h}\right)$ according to the manufacturer.

The grain size GS 10 - $65 \mathrm{~mm}$ was transported via a conveyor belt and samples were able to be taken from the entire dropping area along the entire width with a $60 \mathrm{~L}$ box (sampling location 6 in Figure 1).

The entire oversize fraction GS > $65 \mathrm{~mm}$ (screen overflow) from each test and each trial (1st trial and 2nd trial) was caught directly at the screening outlet with the wheel loader scoop and weighed (sampling location 2 in Figure 1 ) and was placed in intermediate storage 2 for the subsequent post-shredding.

\section{Check Sieve Performance}

In order to determine, how much of the grain size GS $10-65 \mathrm{~mm}$ still remained in the grain size GS > $65 \mathrm{~mm}$, a partial sample was taken ( 1 to 2 wheel loader scoops) of the grain size GS > $65 \mathrm{~mm}$ at the sampling location 2 (GS $>65 \mathrm{~mm}$ sample). This material was sieved a second time (2nd trial) at $65 \mathrm{~mm}$ (Figure 1). The remaining amount of material in the grain size GS $>65 \mathrm{~mm}$, the grain size GS $10-65 \mathrm{~mm}$, after the first screening throughput was determined with approx. $20 \mathrm{M}$-\% for most of the tests. The fraction GS $>65 \mathrm{~mm}$ from this check was also collected in the intermediate storage bunker 2 .

The impact of the second screening of a partial flow of the grain size GS > $65 \mathrm{~mm}$ (screen overflow) was insignificant.

A third screening cycle only exhibits quite a minor impact. Samples of the grain size GS $10-65 \mathrm{~mm}$ were taken from both screening cycles (1st trial and 2nd trial) and the rest were discarded. Since the circular vibratory screen used was equipped with an additional lower deck with $10 \mathrm{~mm}$ mesh size, separate samples of the partial flow of the grain size GS $0-10 \mathrm{~mm}$ (from the 1st trial and the 2nd trial) were taken in addition to that (sampling location 7 in Figure 1) and taken into consideration in the assessment (for more details see chapter 2.2.6 Quality Assurance Laboratory).

\subsubsection{Post-Shredding}

The post-shredding process step was carried out in order to be able to better sample the coarse fraction GS $>65$ $\mathrm{mm}$ for later laboratory tests. A particle size analysis was not provided.

Process: The entire amount (1st trial and 2nd trial) of the grain size GS $>65 \mathrm{~mm}$ was taken from the intermediate storage bunker 2 for each individual trial, and fed via several separators (magnetic separator $1+2$, Eddy current, wind sifter) to the (fine) post-shredder and shredded to a grain 
size of $<10 \mathrm{~mm}$ (GS $0-10 \mathrm{~mm}$ ). The fractions FE1, FE2, non-ferrous and inert were removed from the separators, weighed, samples were taken and the rest was discarded. The shredded material is labelled as GS > $65 \mathrm{~mm}_{\text {„S }} \mathrm{S}^{\prime \prime}{ }_{\text {, }} \mathrm{S}^{\prime \prime}$... shredded).

The shredded material GS $>65 \mathrm{~mm}^{\prime \prime} \mathrm{S}^{\prime \prime}$ from the postshredder was discharged by means of a trough chain conveyor. The sample collection was carried out via a sampling flap (sampling location 5 in Figure 1). The rest was discarded.

Sampling locations and samples obtained from the waste screen and the post-shredder

The following samples were obtained during each trial: The sampling locations are shown in Figure 1.

- Sampling location 1: samples Fe-metals taken for the sorting analyses in the laboratory.

- Sampling location 2: a partial sample of one to two wheel loader scoops taken and sieved once again to determine the screening quality (check sieve performance) in a second cycle (2nd trial). The entire amount of the grain size GS > $65 \mathrm{~mm}$ from cycle one (1st trial) and cycle two (2nd trial) is collected in the intermediate storage bunker 2 and is subsequently shredded with a post-shredder to $<10 \mathrm{~mm}$.

- Sampling locations 3, 4: weighing the material flows Fe, NonFE and inert and representative samples taken for the determining the metal content and the inert content in the laboratory.

- Sampling location 5: representative samples taken from the shredded grain size GS > 65 mm"S" (S=shredded) for determining the chemical and physical fuel parameters in the laboratory.

- Sampling location 6: representative samples taken from the grain size GS $10-65 \mathrm{~mm}$ for screening analyses and determining the chemical and physical parameters of the individual screen categories in the laboratory.

- Sampling location 7: weighing the fine particles of the grain size GS 0-10 $\mathrm{mm}$ and representative samples taken. Aliquot dosage of the grain size GS 0-10 $\mathrm{mm}$ to the samples of the grain size GS $10-65 \mathrm{~mm}$, subsequently screening analysis and after that chemical, physical analysis in the laboratory of the grain sizes obtained from the screening analysis.

\subsubsection{Quality Assurance Laboratory}

The samples of the grain sizes GS $10-65 \mathrm{~mm}$ and GS $0-10 \mathrm{~mm}$ were aliquotly mixed in the laboratory (aliquot mixing of samples) in a mass ratio, such as was obtained during the screening with the waste screen, causing the grain size GS 0-65 $\mathrm{mm}$. The grain size GS 0-65 mm was subsequently sieved with a lab screen in the grain sizes GS 0-20 mm, GS 20-40 $\mathrm{mm}$ and GS 40-65 mm.

These grain sizes and the samples taken of the postshredded material (post-shredder (fine)) GS > 65 mm"S" were subject to chemical and physical analyses.

The chemical and physical analyses were conducted in the laboratory of the Chair of Waste Processing Techno- logy and Waste Management at the Montanuniversitaet Leoben.

Determining the grain size distribution in the grain size GS $0-65 \mathrm{~mm}$

The grain size GS 0 - $65 \mathrm{~mm}$ was sieved with a lab screening machine with the screening holes of $20 \mathrm{~mm}$ and 40 $\mathrm{mm}$.

Resulting from the screening tests on site and the screening analyses in the laboratory are the following grain sizes: GS 0-20 mm, GS 20-40 mm, GS 40-65 mm, GS > 65 mm and GS > $65 \mathrm{~mm}$ "S" after shredding with the post-shredder.

Selecting the screening cuts/screening hole sizes was primarily based on the Austrian Standard ÖNORM EN 15415-1 (Austrian Standards Institute, 2011a). The standard fundamentally recommends a gradual doubling of the hole sizes or mesh size.

\section{Technical data for the laboratory screening machine used}

- Manufacturer: Fritsch, type AS 400 control;

- Dimensions: 400 × 530 x 650 mm (width $\times$ depth $\times$ height);

- Mass: approx. $11 \mathrm{~kg}$ (max), approx. 5 kg (empty);

- Sieve movement: uniform and circular (radius 15mm);

- Speed: 170-180min-1;

- Duration: 7-10min;

- Diameter test sieves: $400 \mathrm{~mm}$.

Determining the metal and inert material contents in all material flows

In order to be able to determine the metal content (FE, nonFE) and inert portion, samples of the individual grain sizes were manually sorted.

\section{Analyses}

The individual grain sizes of each of the trial materials were subject to an in-depth chemical and physical analysis.

The calorific value was determined according to the standard DIN 51900-1 (Austrian Standards Institute, 2000). The inferior calorific value (Hi, TS) is determined at constant volume, the superior calorific value (Hs, TS) at constant pressure. The analyzes were carried out using a device from IKA (type C 7000). The superior calorific value is calculated from the experimentally determined inferior calorific value at constant volume. The calculation is carried out with a given correction factor of $f=0.92$ according to the German RAL Quality Label Directive (May 2001). The conversion takes place according to Hs, TS = $\mathrm{Hi}, \mathrm{TS}$ * 0.92 .

The dry mass was determined according to the standard ÖNORM EN 14343 (Austria Standards Institute, 2007).

The heavy metals content (parameters AVV) was determined according to the standard ÖNORM EN 15411 (ICPMS). (Austrian Standards Institute, 2011b).

AVV: Austrian Incineration Ordinance

\section{RESULTS}

The results of the screening trials on site and the lab tests are shown in detail in the following chapters. 


\subsection{Mass distribution of the individual grain sizes (grain size classes)}

The mass distribution of the investigated grain size classes is shown as bars in Figure 2 for each type of waste and each test. After the individual tests the corresponding average values (arithmetic mean values) are shown for the respective type of waste $(\mathrm{Fi} \varnothing)$ as outlined bar determined in the tests.

The average distribution of the mass to the individual grain sizes for the individual types of waste is as follows:

F1Ø: $50 \%$ of the mass is in the grain size GS $>65 \mathrm{~mm}$, $13 \%$ in the grain size GS $40-65 \mathrm{~mm}, 19 \%$ in the grain size GS $20-40 \mathrm{~mm}$ and $17 \%$ in the grain size GS $0-20 \mathrm{~mm}$. In contrast to the types of commercial waste F2-F4 the amount of the grain size GS $<65 \mathrm{~mm}$ of waste type F1 is higher. With tests on the pre-shredded type of waste F1 (Test T1, T2, T3) it can be seen that no noteworthy fluctuation in the mass distribution of the individual grain sizes appears between the individual tests. These types of waste are much more homogeneous than the types of commercial waste F2 and $\mathrm{F} 3$ due to the standardized collection defined and treatment given (sorting).

When treating these types of waste extensive sheets and hollow items are specifically separated, leaving only small-scale packaging film, screw tops and small hollow items.

F2Ø: $66 \%$ of the mass is in the grain size GS $>65 \mathrm{~mm}$, $12 \%$ in the grain size GS $40-65 \mathrm{~mm}, 10 \%$ in the grain size GS $20-40 \mathrm{~mm}$ and $13 \%$ in the grain size GS 0-20 mm. Great fluctuation appears in the mass distribution of the individual grain sizes between the individual tests.

F3Ø: $63 \%$ of the mass is in the grain size GS $>65 \mathrm{~mm}$, $10 \%$ in the grain size GS $40-65 \mathrm{~mm}, 12 \%$ in the grain size GS $20-40 \mathrm{~mm}$ and $15 \%$ in the grain size GS 0-20 mm. Similar to F2, great fluctuation appears in the mass distribution of the individual grain sizes between the individual tests.

F4Ø: $63 \%$ of the mass is in the grain size GS $>65 \mathrm{~mm}$, $14 \%$ in the grain size GS $40-65 \mathrm{~mm}, 9 \%$ in the grain size GS $20-40 \mathrm{~mm}$ and $14 \%$ in the grain size GS 0-20 mm. A greater fluctuation appears between the grain sizes $0-20 \mathrm{~mm}$ and 20-40 mm.

In contrast to type of waste F1 (Packaging Waste), there were many large plastic films in the Mixed Commercial
Waste types F2, F3 and F4. When using a coarse pre-shredding the plastic films are often only pulled through the cut gap and the tooth gap of the shredders and thus are hardly shredded (selective crushing). This leads to a greater mass portion of the grain size GS > $65 \mathrm{~mm}$ in the types of waste F2, F3 and F4.

\subsection{Calorific value and dry mass}

In the following Figure $3 \mathrm{a}$ ) and b) the calorific values and the dry mass for each grain size and each test material are shown as a bar and the arithmetic mean value for the respective grain sizes are shown as framed bars. In addition, the weighted arithmetic mean values of the calorific values are marked with a dotted line for each type of waste (F1 to F4). It is calculated from the arithmetic mean value of the calorific values of the individual grain classes, taking into account the mass distribution on the individual grain classes.

The calorific value was calculated from the energy value taking the dry mass into consideration.

As is to be expected, the calorific value (arithmetic mean value) rises in most of the cases with the grain size.

F1: the calorific value of $25.2 \mathrm{MJ} / \mathrm{kg}$ in the grain size GS $0-20 \mathrm{~mm}$ is the lowest. Contrary to expectations, the grain size $40-65 \mathrm{~mm}$ exhibits the highest value at 30.1 $\mathrm{MJ} / \mathrm{kg}$. The reason for this deviation was not able to be determined. Relatively large amounts of hollow items (beverage bottles) containing liquids can be found in the grain size GS $>65 \mathrm{~mm}$ and they might have a negative impact on the calorific value. In this case, the high dry substance content of $89 \%$ is an argument against that impact. As is to be expected, the type of waste F1 (packaging waste) exhibits the highest averages (weighted mean value) of calorific values in contrast to types of commercial waste in all grain sizes. The weighted arithmetic mean value of the calorific values is $28.2 \mathrm{MJ} / \mathrm{kg}$;

- F2: the average calorific value at $11.4 \mathrm{MJ} / \mathrm{kg}$ in the grain size GS $0-20 \mathrm{~mm}$ is the lowest. The grain size GS > 65 $\mathrm{mm}$ exhibits the greatest calorific value at $22.5 \mathrm{MJ} / \mathrm{kg}$. In trial T13 (F2 T13) with less than $6 \mathrm{MJ} / \mathrm{kg}$, the type of waste $\mathrm{F} 2$ exhibits in the grain size $0-20 \mathrm{~mm}$ a quite low

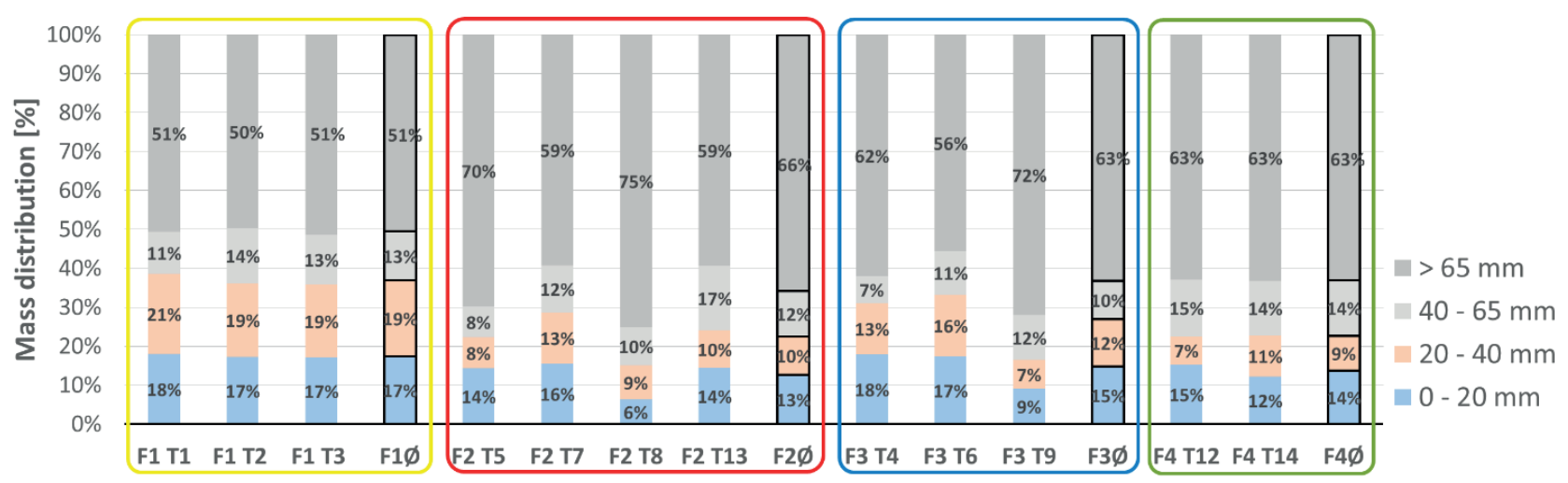

FIGURE 2: Results of the mass distribution of grain size (related to the original substance (OS)) for each waste type and test. 

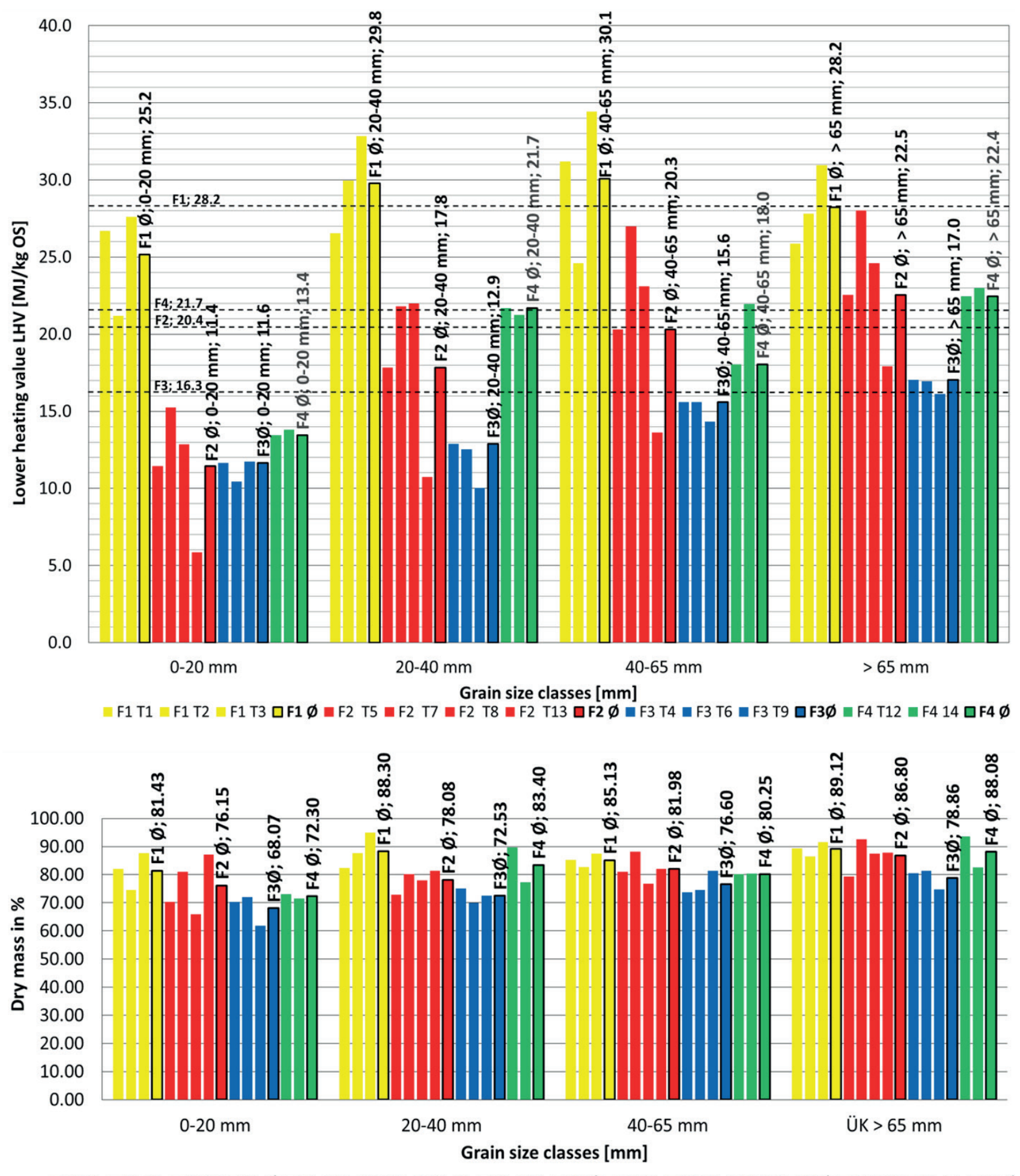

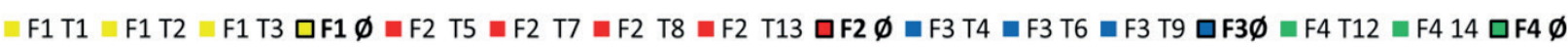

FIGURE 3: a) Results of the calorific values, and b) dry mass for each test material and grain size.

calorific value. The weighted arithmetic mean value of the calorific values is $20.2 \mathrm{MJ} / \mathrm{kg}$;

- F3: the average calorific value at $11.6 \mathrm{MJ} / \mathrm{kg}$ is the lowest in the grain size GS $0-20 \mathrm{~mm}$. The grain size GS > $65 \mathrm{~mm}$ exhibits the greatest calorific value at $17.0 \mathrm{MJ} /$ $\mathrm{kg}$. The fluctuation of the calorific values between the individual tests in the respective grain sizes are rela- tively low. The weighted arithmetic mean value of the calorific values is $16.3 \mathrm{MJ} / \mathrm{kg}$;

F4: the average calorific value at $13.4 \mathrm{MJ} / \mathrm{kg}$ in the grain size GS $0-20 \mathrm{~mm}$ is the lowest. The grain size GS $>65 \mathrm{~mm}$ exhibits the greatest calorific value at 22.4 $\mathrm{MJ} / \mathrm{kg}$. The fluctuation of the calorific values between the individual tests are quite low. The weighted arith- 
metic mean value of the calorific values is $21.7 \mathrm{MJ} /$ $\mathrm{kg}$.

The dry substance (arithmetic mean value) rises in all types of waste with the grain size, as is to be expected. The fluctuation for the individual tests are low.

- F1: The dry substance is between $81.43 \%$ in the grain size GS $0-20 \mathrm{~mm}$ and $89.12 \%$ in the grain size GS > 65 $\mathrm{mm}$. F1 has in all grain size classes the highest dry substance (arithmetic mean value) of all fractions;

- F2: The dry substance is between $76.15 \%$ in the grain size GS $0-20 \mathrm{~mm}$ and $86.80 \%$ in the grain size GS > 65 $\mathrm{mm}$;

- F3: The dry substance is between $68.07 \%$ in the grain size GS $0-20 \mathrm{~mm}$ and $78.86 \%$ in the grain size GS > 65 $\mathrm{mm}$;

- F4: The dry substance is between $72.3 \%$ in the grain size GS $0-20 \mathrm{~mm}$ and $88.08 \%$ in the grain size GS $>65 \mathrm{~mm}$.

\subsection{Chlorine}

In Figure 4, the chlorine content for each grain size and each test material is shown as a bar and the arithmetic mean values of the chlorine are shown as framed bars.

In the grain size GS $20-40 \mathrm{~mm}$ the type of waste F4 exhibits the highest average concentration of chlorine at $4.4 \%$. The type of waste F3 exhibits the lowest concentration in all grain size classes except GS $>65 \mathrm{~mm}$. The types of waste $\mathrm{F} 1$ and $\mathrm{F} 2$ are in the range of $1 \%$. Part of the chlorine content of the type of waste F1 comes from table salt that has remained in the sorting residue of the sorted packaging by clinging onto food packaging or food waste.

\subsection{Metals}

Table 1 summarizes the measured values for the heavy metals according AVV for each test material and grain size class. The values are given as $\%$ of the limit values.

\subsubsection{Antimony}

In the grain size GS $40-65 \mathrm{~mm}$, the type of waste F4 exhibits the highest average values of antimony. The value rises with the grain size in the type of waste $F 1$, and displays an erratic rise which is to be traced back to an accumulation of PET beverage bottles in this grain size. In the types of waste F2 and F3 the highest values are in the grain size GS $>65 \mathrm{~mm}$ as well. All of the values are below the threshold values of the AVV.

\subsubsection{Arsenic}

The type of waste F4 exhibits highest average values of arsenic at $14.2 \%$ for the threshold value in the grain size $\mathrm{GS}>65 \mathrm{~mm}$. All of the values are markedly less than the threshold values of the AVV.

\subsubsection{Lead}

The fraction F3 has the highest lead content across all grain size classes. At $216.4 \%$ the type of waste F3 exhibits the highest values of lead in the threshold value for the grain size GS $20-40 \mathrm{~mm}$. The values of the other types of waste are less than the threshold value.

\subsubsection{Cadmium}

All of the values are markedly below the threshold values of the AVV. No clear trend is discernible.

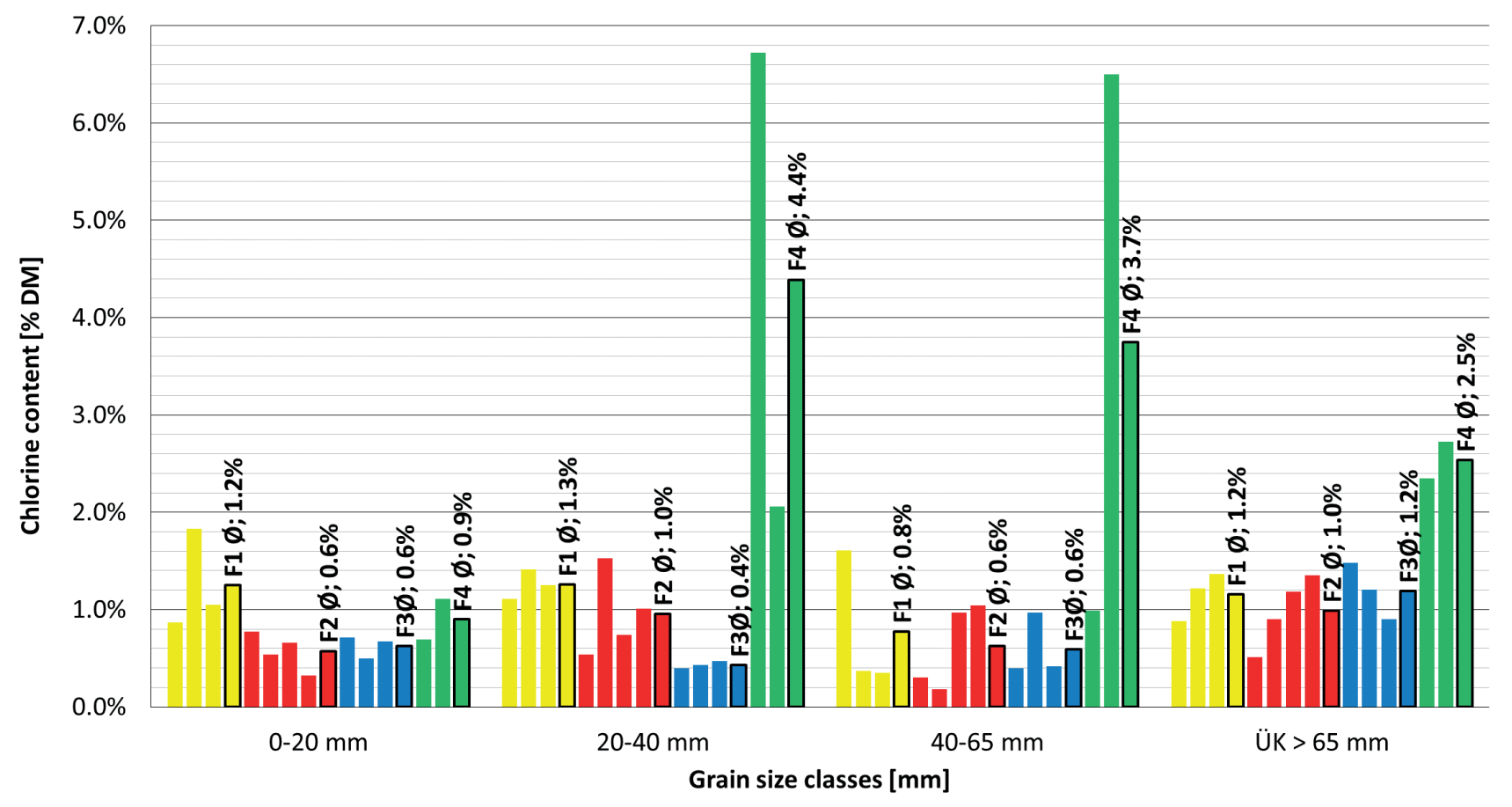

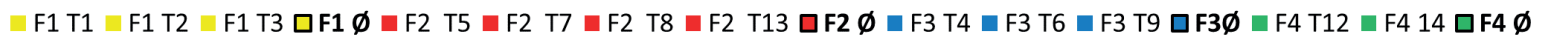

FIGURE 4: Results of the chlorine content [\% DM] in each test material and particle grain size class. 
TABLE 1: Results of the heavy metal content.

\begin{tabular}{|c|c|c|c|c|c|c|c|c|c|c|c|c|c|c|c|c|c|}
\hline & & $\begin{array}{l}\text { F1 } \\
\text { T1 }\end{array}$ & $\begin{array}{l}\text { F1 } \\
\text { T2 }\end{array}$ & $\begin{array}{l}\text { F1 } \\
\text { T3 }\end{array}$ & F1ø & $\begin{array}{l}\text { F2 } \\
\text { T5 }\end{array}$ & $\begin{array}{l}\text { F2 } \\
\text { T7 }\end{array}$ & $\begin{array}{l}\text { F2 } \\
\text { T8 }\end{array}$ & $\begin{array}{c}\text { F2 } \\
\text { T13 }\end{array}$ & $\mathrm{F} 2 \emptyset$ & $\begin{array}{l}\text { F3 } \\
\text { T4 }\end{array}$ & $\begin{array}{l}\text { F3 } \\
\text { T6 }\end{array}$ & $\begin{array}{l}\text { F3 } \\
\text { T9 }\end{array}$ & F3 Ø & $\begin{array}{c}\text { F4 } \\
\text { T12 }\end{array}$ & $\begin{array}{c}\text { F4 } \\
\text { T14 }\end{array}$ & F4ø \\
\hline & & $\%$ & $\%$ & $\%$ & $\%$ & $\%$ & $\%$ & $\%$ & $\%$ & $\%$ & $\%$ & $\%$ & $\%$ & $\%$ & $\%$ & $\%$ & $\%$ \\
\hline \multirow{4}{*}{$\begin{array}{l}\text { Sb median: } 7 \\
\text { [mg/MJ], } 80 \text { th } \\
\text { perzentile: } 10 \\
\text { [mg/MJ] }\end{array}$} & $0-20 \mathrm{~mm}$ & 2,0 & 7,0 & 4,8 & 4,6 & 13,1 & 21,3 & 5,0 & 10,6 & 12,5 & 19,3 & 13,8 & 21,6 & 18,2 & 8,9 & 4,8 & 6,9 \\
\hline & $20-40 n$ & 7,1 & 3,5 & 2,9 & 4,5 & 13,9 & 14,7 & 2,2 & 5,9 & 9,2 & 6,5 & 25,7 & 79,7 & 37,3 & 6,5 & 8,4 & 7,4 \\
\hline & $40-65 \mathrm{~mm}$ & 0,9 & 14,8 & 0,7 & 3,0 & 18,5 & 4,9 & 1,3 & 7,2 & 0,0 & 1,3 & 5,3 & 7,4 & 4,7 & 35,8 & 4,0 & 19,9 \\
\hline & $>65 \mathrm{~mm}$ & 11,0 & 8,4 & 32,5 & 17,3 & 18,1 & 19,1 & 18,4 & 5,8 & 15,4 & 43,9 & 67,0 & 50,8 & 53,9 & 12,8 & 15,3 & 14,1 \\
\hline \multirow{4}{*}{$\begin{array}{l}\text { As median: } 2 \\
\text { [mg/MJ], 80th } \\
\text { perzentile: } 3 \\
\text { [mg/MJ] }\end{array}$} & $0-20 \mathrm{~mm}$ & 2,6 & 2,9 & 2,6 & 2,7 & 9,5 & 5,0 & 4,3 & 30,8 & 12,4 & 4,6 & 5,7 & 4,4 & 4,9 & 14,7 & 4,5 & 9,6 \\
\hline & $20-40 \mathrm{~mm}$ & 2,6 & 2,4 & 2,4 & 2,5 & 3,6 & 3,1 & 3,0 & 37,9 & 11,9 & 3,9 & 4,7 & 12,8 & 7,1 & 3,4 & 6,3 & 4,8 \\
\hline & $40-65 \mathrm{~mm}$ & 2,3 & 2,8 & 2,1 & 2,4 & 3,9 & 2, & 2 & 14,9 & 6 & 3 & 4,0 & 4,7 & 1 & 4,7 & 1 & 3,9 \\
\hline & $>65 \mathrm{~mm}$ & 2,9 & 2,6 & 2,5 & 2,6 & 3,4 & 2,8 & 3,0 & 4,4 & 3,4 & 3,7 & 4,0 & 3,9 & 3,9 & 25,4 & 3,0 & 14,2 \\
\hline \multirow{4}{*}{$\begin{array}{l}\text { Pb median: } 20 \\
\text { [mg/MJ], } 80 \text { th } \\
\text { perzentile: } 36 \\
\text { [mg/MJ] }\end{array}$} & $0-20 \mathrm{~mm}$ & 1,2 & 2,1 & 5,8 & 3,0 & 18,2 & 6,5 & 10,5 & 39,4 & 18,7 & 4,8 & 7,3 & 89,2 & 33,7 & 15,5 & 8,9 & 12,2 \\
\hline & $20-40 \mathrm{~mm}$ & 0,6 & 1,6 & 8,8 & 3,7 & 1,3 & 3,9 & 3,4 & 15,2 & 6,0 & 1,7 & 7,3 & 640,1 & 216,4 & 7,5 & 1,5 & 4,5 \\
\hline & $40-65 \mathrm{~m}$ & 0,3 & 2,1 & 0,6 & 1,0 & 1,0 & 3,1 & 1,4 & 16,7 & 5,6 & 1,5 & 2,9 & 102,6 & 35,7 & 56,8 & 1,1 & 29,0 \\
\hline & $>65 \mathrm{~mm}$ & 3,9 & 2,4 & 13,1 & o & 3, & 8 & 16,7 & 7,5 & 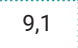 & 10,5 & 6,0 & 48,6 & 21,7 & 10,9 & 9 & 7,9 \\
\hline \multirow{4}{*}{$\begin{array}{l}\text { Cd median: } \\
0.45 \text { [mg/MJ], } \\
\text { 80th perzentile: } \\
0.7 \text { [mg/MJ] }\end{array}$} & $0-20 \mathrm{~mm}$ & 2,9 & 1,3 & 3,6 & 2,6 & 2,6 & 8,4 & 1,8 & 12,2 & 6,2 & 6,6 & 2,5 & 4,4 & 4,5 & 3,6 & 1,9 & 2,7 \\
\hline & $20-40 \mathrm{~mm}$ & 1,1 & 1,0 & 1,0 & 1,1 & 1,6 & 1,3 & 1,3 & 32,5 & 9,1 & 1,7 & 2,0 & 3,3 & 2,3 & 1,4 & 1,3 & 1,4 \\
\hline & $40-65 \mathrm{~mm}$ & 1,0 & 11,1 & 0,9 & 4,3 & 1,7 & 13,5 & 1,2 & 18,9 & 8,8 & 1,6 & 1,7 & 2,0 & 1,8 & 4,0 & 1,3 & 2,6 \\
\hline & 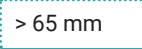 & . & 1 & 1 & 6,5 & 2,1 & 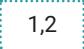 & 1, & 4,4 & 2,3 & 35,4 & 4,0 & 7,3 & 15 & 1,5 & 25,1 & 13,3 \\
\hline \multirow{4}{*}{$\begin{array}{l}\text { Cr median: } 25 \\
\text { [mg/MJ], 80th } \\
\text { perzentile: } 37 \\
\text { [mg/MJ] }\end{array}$} & $0-20 \mathrm{~mm}$ & 4,3 & 2,6 & 3,8 & 3,6 & 20,9 & 18,7 & 6,9 & 108,9 & 38,9 & 29,9 & 102,5 & 6,8 & 46,4 & 21,1 & 12,5 & 16,8 \\
\hline & $20-40 \mathrm{~mm}$ & 0,9 & 0,9 & 0,8 & 0,9 & 2,2 & 6,5 & 3,4 & 47,1 & 14,8 & 10,2 & 36,2 & 13,3 & 19,9 & 1,5 & 1,8 & 1,7 \\
\hline & $40-65 \mathrm{~mm}$ & 0,6 & 0,7 & 0,6 & 0,6 & 1,4 & 8,0 & 1,3 & 42,3 & 13,3 & 6,0 & 64,7 & 8,4 & 26,4 & 3,5 & 1,4 & 2,5 \\
\hline & $>65 \mathrm{~mm}$ & 14,9 & 3,7 & 3,0 & 7,2 & 5,1 & 5,7 & 2,3 & 24,1 & 9,3 & 27,6 & 55,8 & 11,6 & 31,7 & 26,4 & 5 & 14,9 \\
\hline \multirow{4}{*}{$\begin{array}{l}\text { Co median: } 1.5 \\
\text { [mg/MJ], } 80 \text { th } \\
\text { perzentile: } 2.7 \\
\text { [mg/MJ] }\end{array}$} & $0-20 \mathrm{~mm}$ & 2,2 & 6,1 & 3,6 & 4 & 2 & 2 & 10,6 & 9 & 25 & 9,8 & 33 & 19 & 2 & 24 & 2 & 23,0 \\
\hline & $20-40 \mathrm{~mm}$ & 1 & 1 & 0 & 1 & 8, & 5 & 2 & 2 & 58 & 1,2 & 11 & 34,9 & $17, I$ & 3 & 0 & 4,1 \\
\hline & $40-65 \mathrm{~mm}$ & 1,3 & 1,9 & 1,0 & 1,4 & 9,8 & 6,7 & 2,0 & 200,8 & 54,8 & 3,6 & 12,2 & 10,9 & 8,9 & 10,1 & 3,8 & 6,9 \\
\hline & $>65 \mathrm{~mm}$ & 17,9 & 7,2 & 3,3 & 9,5 & 8,3 & 6,1 & 2,5 & 67,7 & 21,2 & 7,1 & 14,9 & 9,5 & 10,5 & 40,8 & 3,9 & 22,4 \\
\hline \multirow{4}{*}{$\begin{array}{l}\text { Ni median: } 1.5 \\
\text { [mg/MJ], 80th } \\
\text { perzentile } 2.7 \\
\text { [mg/MJ] }\end{array}$} & $0-20$ & 30,8 & 28,7 & 20,0 & 26,5 & 70,5 & 124,1 & 76,0 & 829,2 & 275,0 & 77,8 & 536,4 & 33,1 & 215,8 & 126,2 & 76,8 & 101,5 \\
\hline & $20-40$ & 4 & 10,5 & 5, & , & 13,8 & 4 & 26,3 & 392,8 & 1 & 43,1 & 206,9 & 93,9 & 14,6 & 22,5 & 11,7 & 17,1 \\
\hline & $40-65 \mathrm{~mm}$ & 4,0 & 3,2 & 10,3 & 5, & 9, & 41,2 & 6 , & 379,3 & 109,2 & 22,7 & 389,9 & 46,3 & 153,0 & 25,3 & 9,2 & 17,2 \\
\hline & $>65 \mathrm{~mm}$ & 35,7 & 13,8 & 59,1 & 36,2 & 18,0 & 40,5 & 17,2 & 84,0 & 39,9 & 42,9 & 302,2 & 37,8 & 127,7 & 188,5 & 18,9 & 103,7 \\
\hline \multirow{4}{*}{$\begin{array}{l}\text { Hg median: } \\
0.075 \text { [mg/MJ], } \\
\text { 80th perzentile: } \\
0.15 \text { [mg/MJ] }\end{array}$} & $0-20 \mathrm{~mm}$ & 5,1 & 5,9 & 5,3 & 5,4 & 71,4 & 8,9 & 8,5 & 885,6 & 243,6 & 9,2 & 11,5 & 18,2 & 13,0 & 30,5 & 24,2 & 27,4 \\
\hline & $20-40 \mathrm{~mm}$ & 5,2 & 4,9 & 4,8 & 5,0 & 21,2 & 6,1 & 5,9 & 222,2 & 63,9 & 7,8 & 9,3 & 27,5 & 14,9 & 7,0 & 6,1 & 6,5 \\
\hline & $40-65 \mathrm{~mm}$ & 4,6 & 5,6 & 4,2 & 4,8 & 11,7 & 5,4 & 5,5 & 176,7 & 49,9 & 7,3 & 8,0 & 15,9 & 10,4 & 9,5 & 6,1 & 7,8 \\
\hline & $>65 \mathrm{~mm}$ & 5,8 & 5,2 & 4,9 & 5,3 & 20,8 & 5,5 & 5,9 & 69,1 & 25,3 & 7,4 & 8,0 & 64,6 & 26,7 & 53,7 & 6,1 & 29,9 \\
\hline
\end{tabular}

\subsubsection{Chromium}

All of the average values of the individual types of waste are less than the threshold value. In the grain size GS 0-20 $\mathrm{mm}$ the fraction F2 T13 at 108.9\% exceeds the threshold value and the fraction F3 T6 at $102.5 \%$ slightly exceeds the threshold value of the AVV. All of the other values are markedly lower than the threshold values of the AVV. No clear trend is discernible.

\subsubsection{Cobalt}

The type of waste F2 exhibits the highest average values for Cobalt for the threshold value in the grain size GS $0-20 \mathrm{~mm}$ at $250.7 \%$.

Individual test materials of the type of waste F2 exceed the threshold value in the grain sizes GS 0-20 mm at $939.7 \%$, GS $20-40 \mathrm{~mm}$ at $218.9 \%$ and GS $40-65 \mathrm{~mm}$ at $200.8 \%$. The reason for these high values was not able to be determined. All of the other values are markedly below the threshold values of the AVV. The values are higher in the smaller grain sizes.

\subsubsection{Nickel}

In all types of waste with the exception of the type of waste $\mathrm{F} 1$ there is in part a high level of threshold value exceedance. The type of waste F2 in the grain size GS 0-20 $\mathrm{mm}$ at $829.2 \%$ has the highest exceedance and an average value of $275.0 \%$, the values drop with increasing grain size, and falls well below the threshold value in the grain size 
$\mathrm{GS}>65 \mathrm{~mm}$. The average values of the type of waste F3 exceed the threshold value in all grain sizes, whereby the highest values are in the grain sizes GS 0-20 mm and GS 40$65 \mathrm{~mm}$. The average values of the type of waste F4 exceed the threshold value in the grain sizes GS > $65 \mathrm{~mm}$ and GS 0-20 $\mathrm{mm}$. The reason for these high values was not able to be determined. It is discernible that the highest values are found in the small grain sizes.

\subsubsection{Mercury}

The type of waste F2 in the grain size GS $0-20 \mathrm{~mm}$ has the highest values at a threshold value exceedance of $885.6 \%$ in the test material F2 T13. The values drop with increasing grain size and in the grain size GS > $65 \mathrm{~mm}$ are markedly less than the threshold value. The values of all of the other types of waste are markedly less than the threshold value of the AVV.

\section{DISCUSSION}

In the following chapters, the results or values from the individual chemical investigations are summarized and discussed. The arithmetic mean values are the mean values of the individual grain classes from several experiments with the same type of waste. The weighted arithmetic mean values across all grain sizes correspond to the value of each type of waste prior to screening.

\subsection{Calorific values}

In Figure 5 the arithmetic mean values of the calorific values of the individual grain sizes are shown as bars and the weighted arithmetic mean (weighted average) values for each type of waste are shown as framed bars.
As is to be expected the calorific value (arithmetic mean value) rises in most of the cases with the grain size.

The weighted average of the arithmetic mean values of the respective grain classes is for:

- F1: $28.2 \mathrm{MJ} / \mathrm{kg}$. The type of waste F1 (packaging waste) is relatively homogeneous since the processing and collection are precisely defined process stages. This fact is also reflected in the results of the chemical and physical analyses. The material is quite dry and thus also has a quite high calorific value in the small grain size ranges;

- F2: $20.4 \mathrm{MJ} / \mathrm{kg}$;

- F3: $15.59 \mathrm{MJ} / \mathrm{kg}$;

- F4: $20.50 \mathrm{MJ} / \mathrm{kg}$.

\subsection{Chlorine}

Figure 6 shows the arithmetic mean values of the chlorine levels of the individual grain sizes shown as bars and the weighted arithmetic mean values for each type of waste shown as framed bars.

The weighted arithmetic mean chlorine values of the respective grain sizes (classes) is for:

- F1: $1.14 \%$. The differences between the individual grain sizes are slight.

- F2: $0.890 \%$.

- F3: $0.959 \%$. The small grain sizes contain less chlorine than the grain size $>65 \mathrm{~mm}$ and show with values between 0.4 and $0.6 \%$ the lowest $\mathrm{Cl}$ values.

- F4: $2.65 \%$. Rather great differences appear between the individual grain sizes. The maximum value of all of the test materials of $4.4 \%$ was measured in the grain size GS $20-40 \mathrm{~mm}$. Thus this material can only be pro-

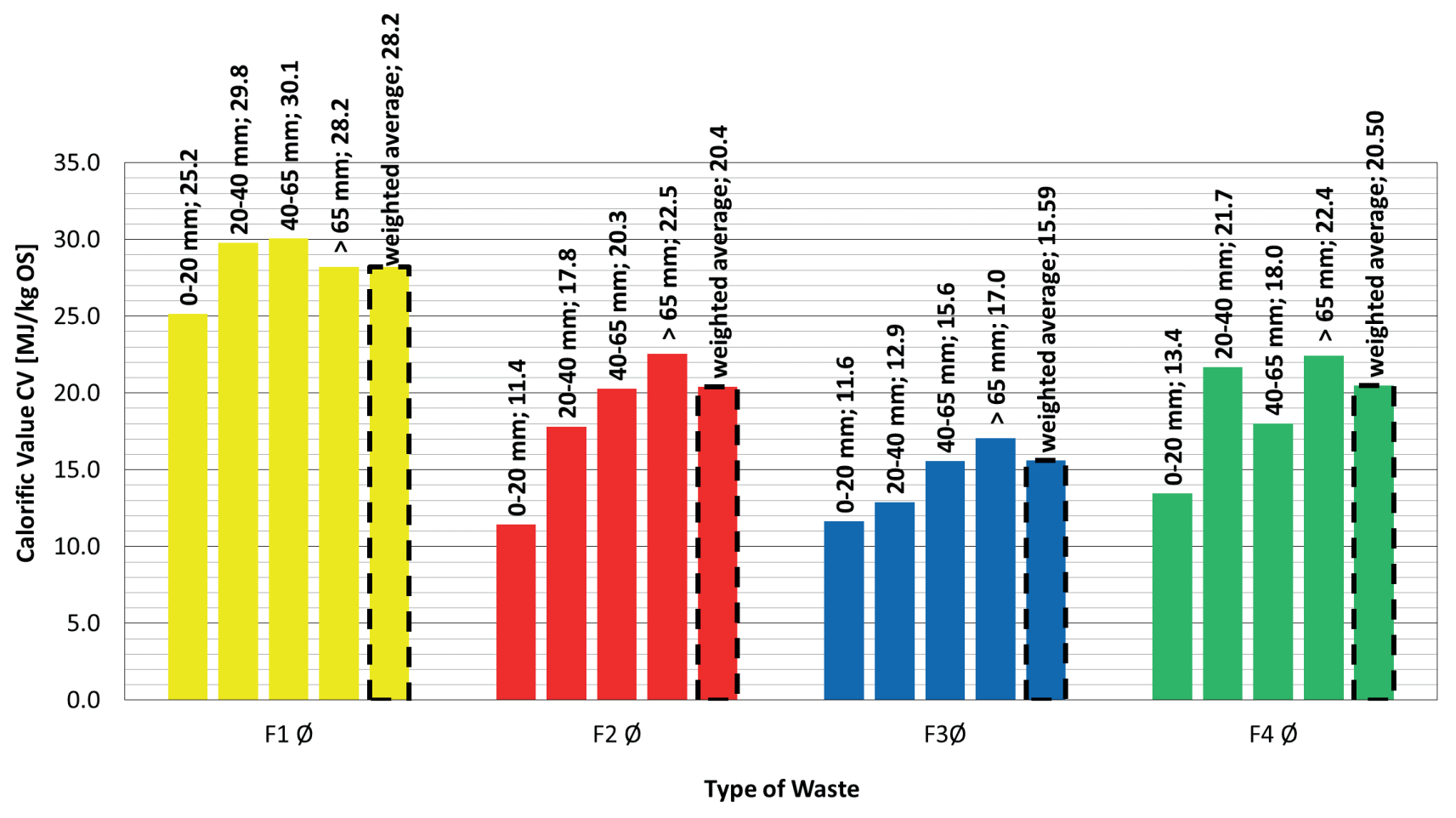

FIGURE 5: Calorific values of the types of waste examined. 


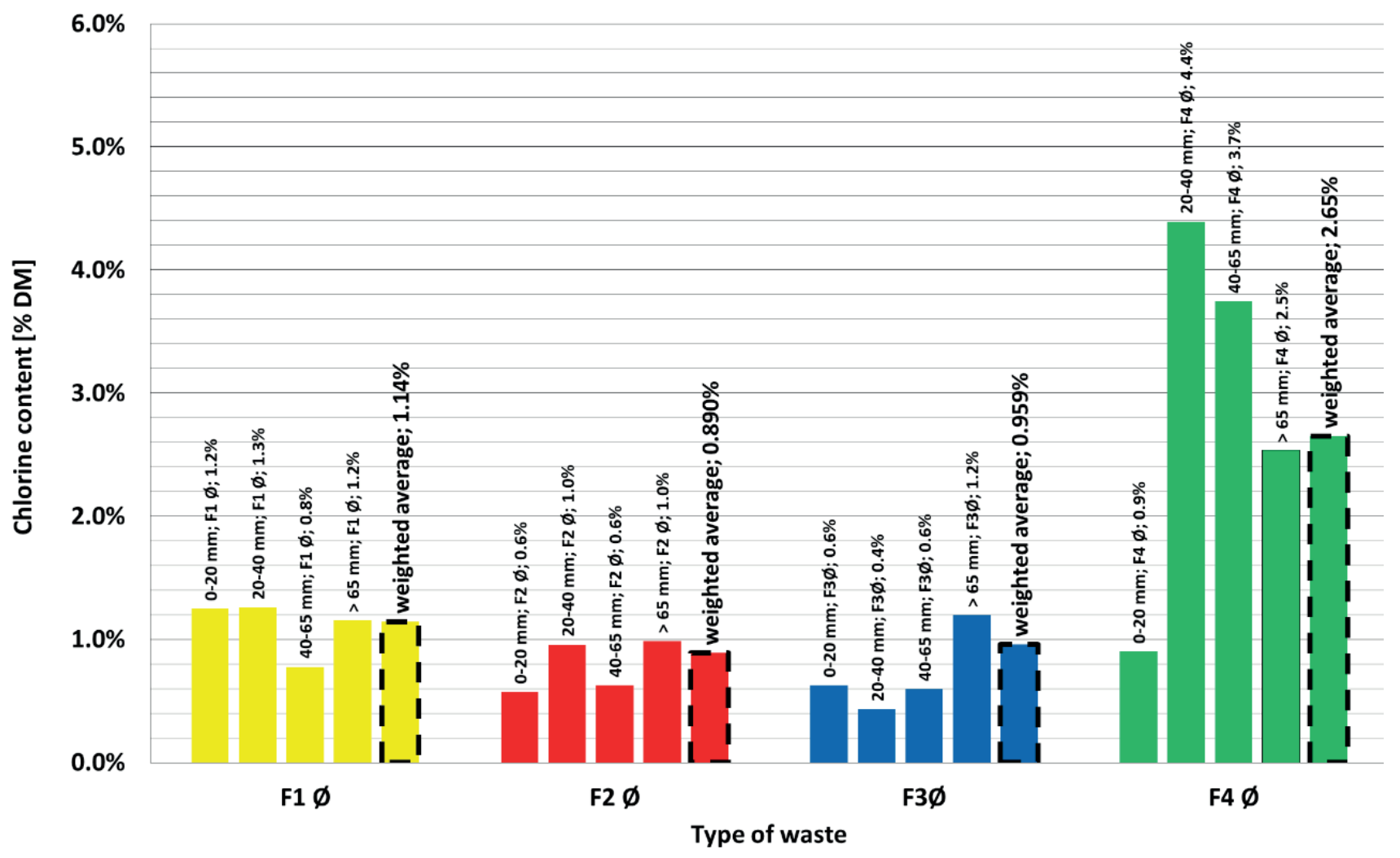

FIGURE 6: Chlorine levels of the types of waste examined.

cessed into substitute fuel as a mixture with other low chlorine waste.

\subsection{Heavy metals}

In Figure 7 the threshold value exhaustion for heavy metals is shown as a percentage of the threshold values for each type of waste and grain size. In addition, the weighted mean values (weighted average w.a. = average value) for the respective heavy metal for each type of waste are also shown as black bars. The weighted mean value is the value of the entire respective type of waste prior to the screening.

Most of the mean values (weighted arithmetic mean values) of the individual types of waste are lower than the threshold values of the AVV. The reasons for individual threshold value exceedance were not able to be determined.

- F1: The values for all parameters in all grain sizes are markedly lower than the threshold values of the AVV.

- F2: Most of the values are markedly lower than the threshold values of the AVV. Individual threshold value exceedance can be found in the grain size GS 0-20 mm for $\mathrm{Co}, \mathrm{Ni}$ and $\mathrm{Hg}$ as well in grain sizes GS $20-40 \mathrm{~mm}$ and GS 40-65 mm for $\mathrm{Ni}$. The weighted arithmetic mean is below the threshold values.

- F3: Most of the values are markedly less than the threshold values of the AVV. The weighted arithmetic mean value for $\mathrm{Ni}$ exceeds the threshold value with $138.5 \%$ markedly. Individual threshold value exceedance can be found in all grain sizes for $\mathrm{Ni}$ and in grain size GS $20-40 \mathrm{~mm}$ for lead.

- F4: Most of the values are markedly lower than the th- reshold values of the AVV. Individual slight threshold value exceedance can be found in the grain sizes GS 0-20 $\mathrm{mm}$ and $\mathrm{GS}>65 \mathrm{~mm}$ for $\mathrm{Ni}$. The weighted arithmetic mean values for all parameters are lower than the threshold values of the AVV.

\section{CONCLUSIONS}

The quality in the various grain sizes of the types of waste examined fluctuated quite heavily. The calorific values are higher such as is to be expected in the larger grain sizes. The highest calorific value is to be found in the type of waste F1. The chlorine levels are with the exception of F4 (2.65\%) lower and can be found in the range of $1 \%$. The mean values (weighted arithmetic mean values) of the heavy metal contents are markedly less than the threshold values of the AVV.

But the type of waste $\mathrm{F} 2$ exceeds the threshold value in some grain sizes for $\mathrm{Ni}, \mathrm{Hg}$ and $\mathrm{Co}$. In the type of waste F3 the weighted mean value exceeds the Ni-threshold value markedly with $138.5 \%$. The cause for the exceedance was not able to be determined.

Basically all types of waste are suitable for the production of SRF:

F1: The high-calorific type of waste F1 (Packaging Waste) is ideally suitable for the production of SRF. The type of waste F1 can compensate for lower calorific value types of waste, such as e.g.F3, however it exhibits higher chlorine levels which in turn are evened out by the low chlorine types of waste; 


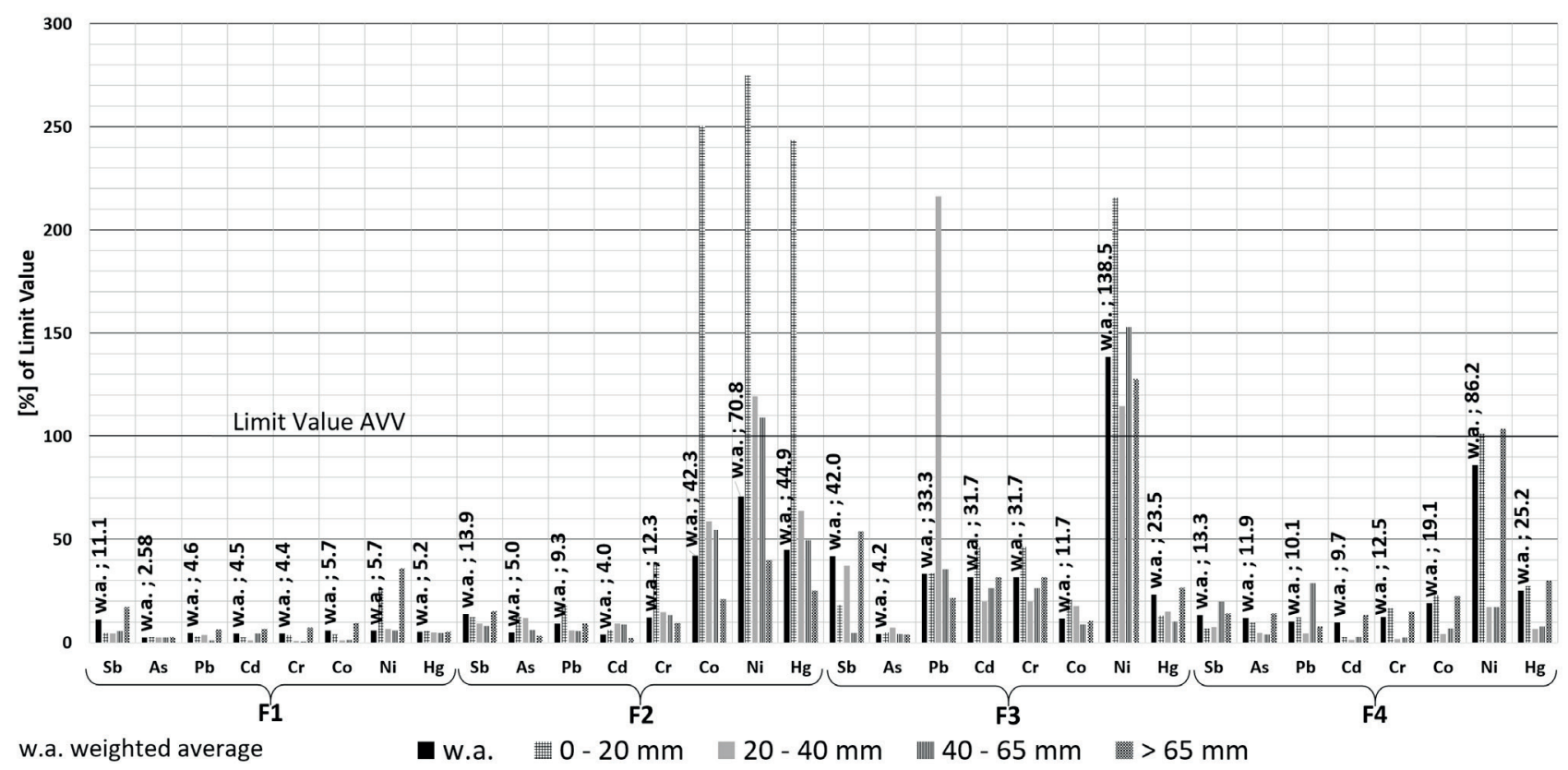

FIGURE 7: AVV parameters (heavy metals) of the types of waste F1, F2, F3 and F4 examined.

- F2: The type of waste F2 (Mixed Commercial Waste 1) is suitable in the mixture with other high-calorific waste for the production of SRF;

- F3: The type of waste F3 (Mixed Commercial Waste 2) can be used in the mixture with other types of waste with higher calorific values as an input material for the production of SRF particularly as they display relatively low chlorine values;

- F4: The type of waste F4 (Mixed Commercial Waste 3 ) is suitable due to the high chlorine values only in the mixture with low chlorine waste for the SRF production.

None of the types of waste are suitable as a monofraction for the production of substitute fuels or for the direct use in the cement facilities' processes (e.g. to low heating value, to high water content, to high chlorine content etc.). It is the right mixture that produces the flexibility important to be able to produce high quality assured substitute fuels. Disadvantageous properties, such as higher chlorine values or lower calorific values of individual types of waste or individual batches, can thus be compensated, thereby allowing to ensure constant and stable quality properties and high substitution rates.

\section{CONFLICT OF INTEREST}

The authors declare no conflict of interest.

\section{ACKNOWLEDGEMENTS}

The Center of Competence for Recycling and Recovery of Waste 4.0 (acronym ReWaste4.0) (contract number 860 884) under the scope of the COMET - Competence Centers for Excellent Technologies - financially supported by BMVIT, BMWFW and the federal state of Styria, managed by the FFG.

\section{REFERENCES}

Aldrian, A., Sarc, R., Pomberger, R., Lorber, K.E., Sipple, E.-M., 2016. Solid recovered fuels in the cement industry-semi-automated sample preparation unit as a means for facilitated practical application. Waste management \& research: the journal of the International Solid Wastes and Public Cleansing Association, ISWA 34 (3), 254264. $10.1177 / 0734242 \times 15622816$.

Austrian Standards Institute, 2000. DIN 51900-1 Prüfung fester und flüssiger Brennstoffe - Bestimmung des Brennwertes mit dem Bomben-Kalorimeter und Berechnung des Heizwertes - Teil 1: Allgemeine Angaben, Grundgeräte, Grundverfahren (Testing of solid and liquid fuels - Determination of the calorific value with the bomb calorimeter and calculation of the calorific value - Part 1: General information, basic equipment, basic method).

Austrian Standards Institute, 2007. ÖNORM EN 14343 Charakterisierung von Abfällen - Berechnung der Trockenmasse durch Bestimmung des Trockenrückstandes oder des Wassergehaltes (Characterization of waste - Calculation of waste Dry matter by determination of the Dry residue or water content).

Austrian Standards Institute, 2011a. ÖNORM EN 15415-1 Feste Sekundärbrennstoffe - Bestimmung der Partikelgrößenverteilung Teil 1: Siebverfahren für kleine Partikel (EN 15415-1 Solid recovered fuels - Determination of particle size distribution Part 1: Screening method for small particles). Österreichisches Normungsinstitut (ON), Wien. (Last access: 6 February 2019)

Austrian Standards Institute, 2011b. ÖNORM EN 15411 (ICP-MS Feste Sekundärbrennstoffe - Verfahren zur Bestimmung des Gehaltes an Spurelementen (As, Ba, Be, Cd, Co, $\mathrm{Cr}, \mathrm{Cu}, \mathrm{Hg}, \mathrm{Mo}, \mathrm{Mn}, \mathrm{Ni}, \mathrm{Pb}, \mathrm{Sb}$, Se, TI, V und Zn) (Solid secondary fuels - Method for determining the content of trace elements (As, Ba, Be, Cd, Co, Cr, Cu, Hg, Mo, $\mathrm{Mn}, \mathrm{Ni}, \mathrm{Pb}, \mathrm{Sb}, \mathrm{Se}, \mathrm{Tl}, \mathrm{V}$ and $\mathrm{Zn}$ ).

Bundeskanzleramt, 2010. Austrian Incineration Ordinance https:// www.ris.bka.gv.at/GeltendeFassung.wxe?Abfrage=Bundesnorm en\&Gesetzesnummer=20002239 (Last access: 27. march 2019).

Feil, A., Pretz, T., 2018. Unused potential in waste processing. Recy \& DepoTech 2018_ conference book presentations.pdf, in: Recy \& DepoTech 2018_ conference book presentations , Vol. 1, 153160.

IFE Aufbereitungstechnik GmbH, 2019. Waste screens: Brochure Waste screens. Last access: 31 January 2019.

Lorber, K.E., Sarc, R., Aldrian, A., 2012. Design and quality assurance for solid recovered fuel. Waste management \& research : the journal of the International Solid Wastes and Public Cleansing Association, ISWA 30 (4), 370-380. 10.1177/0734242X12440484. 
Mauschitz, G., 2018. Emissionen aus Anlagen der Österreichischen Zementindustrie Berichtsjahr 2017 (Emissions from Austrian cement industry reporting year 2017). Available online at: https://www. zement.at/beton-2/nachhaltigkeit-und-umwelt/emissionen. (Last access: 01 march 2019).

Sarc, R., Lorber, K.E., 2013. Production, quality and quality assurance of Refuse Derived Fuels (RDFs). Waste management (New York, N.Y.) 33 (9), 1825-1834. 10.1016/j.wasman.2013.05.004.

Sarc, R., Lorber, K.E., Pomberger, R., Rogetzer, M., Sipple, E.M., 2014. Design, quality, and quality assurance of solid recovered fuels for the substitution of fossil feedstock in the cement industry. Waste management \& research : the journal of the International Solid Wastes and Public Cleansing Association, ISWA 32 (7), 565-585. 10.1177/0734242X14536462.

Sarc, R, Pomberger, R, Eferdinger, S., 2015. „REUQ-Ausweis“ für EBS Entwicklung eines Ressourcen-, Energie-, Umwelt-, Qualitätsausweises (REUQ) für Ersatzbrennstoffe (EBS) ("REUQ certificate" for SRF Development of a resource-, energy-, environmental-, quality certificate (REUQ) for solid recovered fuels (SRF), Association of Austrian Waste Management Companies (VÖEB)), Verband Österreichischer Entsorgungsbetriebe (VÖEB), Wien, Austria. 